\title{
Transaction Costs in Option Pricing: An Extension Model
}

\author{
Yunze Dong ${ }^{1, a}$ \\ ${ }^{1}$ School of Accounting and Finance, University of Bristol, Bristol, United Kingdom \\ aal18910@bristol.ac.uk
}

\begin{abstract}
This paper is divided into two parts. First, we consider a modified version of the Black-Scholes option pricing model which takes transaction costs into consideration by combining knowledge of Brownian Motion and Ito Process with mathematical tools of calculus, probability theory and mathematical statistics. Further, the solution of the model illustrates that introducing transaction costs greatly alters the levels of volatility. In part two, this paper illustrates plots of the result of the modified model by using python and empirical analysis by using R. It is found that the frequency of transaction volume adjustments and the ratio of transaction costs to call and put option results exhibit opposite behaviours in plots of result. What's more, in empirical analysis, the modified model also gives a better simulation compared to original B-S model. Finally, further issues related to transaction costs are discussed.
\end{abstract}

Keywords: option pricing, transaction cost, Black-Scholes model

\section{INTRODUCTION}

\subsection{Research Background and Significance}

In 1973, the world's first options exchange was established - CBOE (Chicago Board Options Exchange). It marked the beginning of an era, one of truly organised options trading. In the same year, two professors from the University of Chicago, Fisher Black and Myron Scholes, published a paper entitled The Pricing of Options and Corporate Liabilities which was instrumental in making the pricing of options possible. In the first half of 2020, the trading volumes of options in world markets reached 9.6 billion options with a $32.43 \%$ year-on-year growth which broke historical records.

In 1900, Louis Bachelier first tried to connect stochastic motions and fluctuations of price. Then, in the early 1950s, Samuelson, the inventor of option terms "European" and "American", discovered Louis's work. Finally, in 1973, the famous Black-Scholes model was established by Fisher Black and Myron Scholes. After the 1990s, although the model was found to have many limitations and received a myriad of academic criticism, traders in Wall Street started to regard it as a benchmark, because it provides such a valuable intuition. Moreover, these models play an important role in determining the value of financial derivatives and other assets, and even the concept of goodwill, which has only recently been incorporated into corporate assets accounts. The reason as to why we are still accustomed to naming these models as options pricing models is because these models are generated in the field of options pricing, and many scholars usually use relevant concepts of options as a bridge between mathematical models and their economic significance.

In the option pricing model, there is often an underlying premise that no room is left for arbitrage in the market. However, in practical application, trading institutions can use the derivative pricing model to compare the prices of different financial derivatives of the same asset, including (but not limited to) futures and options of different types, periods and prices. In this way, trading institutions can ascertain which derivatives are unreasonably priced, so as to realise spatial arbitrage. In fact, this is precisely because the derivative pricing model can bring financial institutions such a relatively stable means of generating profits. Through a series of option pricing methods, Ito [8] himself was almost hailed as a deity in Wall Street. At the same time, because of its strong applicability, option pricing is still one of the hottest topics in the field of scientific research.

In the article published by American financial scientists and mathematicians Fisher Black and Myron Scholes, the European option pricing model with no transaction cost and no dividend payment as based on the 
Wiener process appeared for the first time, also known as the Black-Scholes option pricing model. Yet this basic model cannot always sufficiently adapt to the current market. Under market economy conditions, the existing arbitrage space will die out with the popularisation of advanced technology and management experience, which is also one of the manifestations of the intrinsic market regulation mechanism Undoubtedly, there is no exception in the financial market, which causes people to necessarily constantly optimise their original model, so that they can regain technical superiority, and thereby seek new opportunities for profit generation.

Thus, in order to adapt to the changing rules of market capital price changes, a model is required that can remain more in line with the reality of the market. In the original Black Scholes option pricing model, transaction expenses (costs) were not added to the model as a variable, but such cost, whilst being neglected, are material to traders. However, in the actual transaction, facing different customers of the exchange, there may be completely different transaction fee charging rules for different derivative products of the same subject, or different transaction quantities of the same derivative product. In particular, when some investors frequently trade in order to (as much as possible) mitigate risks while generating a small profit, the transaction cost will gradually become significant with the increase of transaction times and thus cause the initial model to gradually deviate from the actual situation. For this reason, in this paper, we will mainly discuss the European option pricing model which includes transaction costs. Although our extension option pricing model is based on European options, it provides a lower bound for pricing American options.

\subsection{Research Status and Literature Review}

The idea of options can be traced back to the Code of Hammurabi, around 1800 BC, and as early as 1200 BC in ancient Greece; moreover, the ancient Rich Nikki country trade has appeared as the prototype of options trading, but it is impossible to have a deep understanding of options under the chronologically specific conditions of those times, insofar that our understanding is bound to be anachronistic. In the field of option pricing, prior to the establishment of the Black-Scholes option pricing model, a great deal of research had been undertaken into option pricing. The first model is published in a paper entitled "Speculative Theory", a doctoral thesis by the French mathematician Bachelier Louis in 1900. This paper assumes stock price changes obey normal distribution, and the price movement uninterrupted, and averages the same, there is no arbitrage opportunity without having to pay a dividend. He assumes that the stock price change process is a no-drift and per-unit time variance of pure standard Brownian motion.

The parameter $\pi$ is the amount of market "price leverage" adjustment, and $\alpha$ is the expected return on stocks. However, the model does not take into account the time value of money. The idea of a stochastic process plays an important role in options pricing. Ito [8] proposed the Ito process and Ito lemma. He pointed out the rules for differentiating a function of a random process. Emanuel Parzen [6] was to later systematically explain the mathematical basis of Brownian motion and random motion. As early as 1971, Fischer Black [3] discussed the main factors influencing the pricing of stocks and options, such as volatility, strike price, and maturity. On this basis, Fischer Black and Myron Scholes [1] proposed the famous B-S option pricing model. The birth of the B-S model marks the establishment of modern option theory. Black Fisher [2] verified the feasibility of futures price valuation with the B-S formula. Geske [7] calculated the intrinsic value of compound options by using the B-S formula. Chiras and Manaster [5] use the B-S model to verify the efficiency of the market. However, because the B-S model lacks an effective measure of expected return or risk aversion, Robert Merton [11] introduced a risk-neutral or martingale representation on the B-S model, thus further perfecting the it into the B-S-M model. Mittnik [12] introduces the way of valuing option pricing for stable and infinitely divisible asset returns.

With the deepening of practice, the research shows that the assumptions involved in the B-S options pricing model are often subject to various constraints and limitations in real market applications. For example, many empirical studies substitute real option price data into a B-S formula to invert implied volatility. However, in general, implied volatility is not a simple constant, but a variable that presents a U-shaped curve (volatility smile curve). Thus, the assumption that volatility is constant during stock price movements is often rendered void. Therefore, scholars attempted to add new factors into the model to modify the model, such as the constant elastic volatility model (CEV) [9] , jump diffusion pricing model [11] and so forth. The B-S pricing model not only contains many inherently uncertain factors in advance, but is also less suitable for path-dependent option pricing. Bouchaud [4] discussed the disadvantages of the BS model from the perspective of mathematics and statistics. John, Gilster and William [10] stated that the impact of transaction costs and difference between borrowing rate and lending rate would offset each other. Wilmott, P. and Hoggard, T. and Whalley, A. Elizabeth. [13] derived the differential equation for the option pricing with consideration of transaction costs.

\subsection{Main Research Contents and Innovations}

At present, different options contracts resulting from different taxes, different exchanges and different contract standards can have completely different trading fee rules. Transaction cost is an important factor affecting the option price. In this paper, we discuss the transaction 
costs in two parts: in the first part, the assumptions of the original BS model would be a verified and adjusted option pricing model with transaction costs established. Then, some further issues about transaction costs shall be discussed. In the second part, instances and empirical analysis by using recent data of our applied adjusted model will be given and analysed. Then, the volatility and real-world example combined with Greek letters is further considered.

\section{EXTENSION MODEL}

\subsection{Black-Scholes Option Pricing Model and Its Extension}

The revolution of modern option pricing theory began in the 1970s. Fischer Black and Myron Scholes [1] deduced the famous Black-Scholes Option Pricing Model in their paper entitled The Pricing of Options and Corporate Liabilities, and they applied it to the pricing of European options, which resulted in great repercussions within the academic community. However, the BlackScholes option pricing model has quite strict assumptions, including no transaction expenses (costs) and no dividend payment and other ideal conditions, which are greatly divorced from reality. For this reason, the original BlackScholes option pricing model has been subsequently optimised to being it more in line with realistic requirements, and has become one of the focuses of the establishment of the option pricing model. In this paper, the Black-Scholes option pricing model, with simple transaction expenses, shall be introduced, and the composition of transaction costs will be further discussed.

\subsection{Black-Scholes Derivative Pricing Model}

It should be made clear that the Black-Scholes option pricing model is actually an idealised model, containing the following assumptions:

(1) There is no opportunity for risk-free arbitrage in the market;

(2) The market allows for short selling;

(3) Derivatives and securities trading have no transaction fees nor taxes applied (such as stamp duty);

(4) Securities trading is continuous, and price movements are continuous rather than discontinuous;

(5) All securities are perfectly separable;

(6) Fluctuations of stock price are subject to the Brownian motion;

(7) Within the term specified in the option contract, that is, within the term of the derivative, the risk-free continuous compound interest rate $r$ shall be constant;

(8) Within the validity period of the contract, cash income (such as dividend payments) does not exist.
These assumptions are far too idealised to reflect realworld transactions. For instance, assumption (4) cannot be achieved unless the assets traded have extreme liquidity. In reality, markets of assets and derivatives usually utilise a bid-ask pattern or market-maker system to fit and ensure the liquidity of the market. We can always find discontinuous price movements in life. What's more, assumption (7) is also impractical, insofar that the interest rate always varies with monetary policy.

Yet these assumptions simplify a complex problem as much as possible and highlight the core issue of utmost concern, namely, the relationship between the price of the underlying assets and the price of derivatives. Although the above assumptions do not render the model sufficiently accurate, our subsequent improvements need to be based on this model, which provides a clear foundation and developmental direction for subsequent models. In this paper, the assumption (3) will be further solved by adding transaction costs to the model.

\subsection{Extension Model of Option Pricing with Transaction Costs}

The European call options (with transaction costs) are analysed. In the actual situation, transaction costs may include the service charge, intermediary fee, stamp duty and other expenses. In this model, we assume that all transaction costs come from the additional expenses based on the price of underlying asset incurred in the transaction for the convenience of calculation. Then, the transaction cost should be $k|n| S$

Where:

$k \quad-\quad$ The ratio of transaction costs on the price of stock,

$n$ - The amount of the subject matter of derivatives,

$S \quad$ - The prices of the stock.

By adding this transaction cost to the original B-S Model, we can obtain:

$$
\begin{gathered}
c=S_{t} N\left(d_{1}\right)-X e^{-r(T-t)} N\left(d_{2}\right) \\
d_{1}=\frac{\ln \left(\frac{S_{t}}{X}\right)+\left(r+\frac{b_{1}^{2}}{2}\right)(T-t)}{b_{1} \sqrt{T-t}} \\
d_{2}=\frac{\ln \left(\frac{S_{t}}{X}\right)+\left(r-\frac{b_{1}^{2}}{2}\right)(T-t)}{b_{1} \sqrt{T-t}}=d_{1}-b_{1} \sqrt{T-t} \\
b_{1}^{2}=b^{2}-2 \sqrt{\frac{2}{\pi \Delta t}} k b
\end{gathered}
$$

(for calculation details, see Appendix I)

The above equation is the solution of the extension model of European call options with transaction costs included. We can find that volatility would actually change when transaction costs are introduced. 
Furthermore, to satisfy the model, $k$ should be less than $b \sqrt{\frac{\pi}{8}} \sqrt{\Delta t}$, which means that neither the transaction ratio would be too little nor the hedging would be too frequent.

\subsection{Further Discussion in Transaction Costs}

There are several questions which need to be explored regarding the essence of transaction costs. As transaction costs are any additional expenses incurred in the transaction, some expenses are not actually based on the price of underlying assets and are subject to constant change.

In the first place, the expenses caused by price changes in one transaction can hardly be determined accurately. Generally, prices of assets with low liquidity would obviously react to the relevant transactions, and even the prices of assets with high liquidity would appear to apparently change when the deal volume is startling high. Additionally, the bid-ask spread would be evidently determined by liquidity as well. The spread tending to be narrower for those assets which are frequently traded, and to be wider for those which are not.

Therefore, the ratio $k$ is knotty to determine and requires further research.

\section{APPLICATION CASE AND EMPIRICAL ANALYSIS}

\subsection{Option Price}

Based on the research discussed in the previous chapter, we obtain the differential equation models of option pricing, with and without transaction costs. Next, we will introduce specific examples for calculation.

Suppose a stock with a maturity of one year has a present value of 23 Yuan, an exercise price of 20 Yuan, with a risk-free interest rate of $6 \%$ per year, price volatility of $20 \%$, and a transaction cost ratio of 0.001 .

So, in this case,

$$
\begin{gathered}
S_{t}=23 \\
X=20 \\
r=0.06 \\
b=0.2 \\
T-t=1 \\
k=0.001
\end{gathered}
$$

Further, we start by assuming that the trader does not adjust the transaction share very frequently $(\Delta t=0.5)$. First, we calculate the price of European call options without transaction costs. The pricing formula is as follows:

$$
\begin{gathered}
c=S_{t} N\left(d_{1}\right)-X e^{-r(T-t)} N\left(d_{2}\right) \\
d_{1}=\frac{\ln \left(\frac{S_{t}}{X}\right)+\left(r+\frac{b^{2}}{2}\right)(T-t)}{b \sqrt{T-t}} \\
d_{2}=d_{1}-b \sqrt{T-t}
\end{gathered}
$$

Whereby, we arrive at:

$$
c=4.5112
$$

The following is the pricing formula of European put options without transaction costs:

$$
\begin{gathered}
p=X e^{-r(T-t)} N\left(-d_{2}\right)-S_{t} N\left(-d_{1}\right) \\
d_{2}=\frac{\ln \left(\frac{S_{t}}{X}\right)+\left(r+\frac{b^{2}}{2}\right)(T-t)}{b \sqrt{T-t}} \\
d_{2}=d_{1}-b \sqrt{T-t}
\end{gathered}
$$

We arrive at:

$$
p=0.3465
$$

The following is the pricing formula of European call options with transaction costs:

$$
\begin{gathered}
c=S_{t} N\left(d_{1}\right)-X e^{-r(T-t)} N\left(d_{2}\right) \\
d_{1}=\frac{\ln \left(\frac{S_{t}}{X}\right)+\left(r+\frac{b_{1}^{2}}{2}\right)(T-t)}{b_{1} \sqrt{T-t}} \\
d_{2}=d_{1}-b_{1} \sqrt{T-t} \\
b_{1}^{2}=b^{2}-2 \sqrt{\frac{2}{\pi \Delta t}} k b
\end{gathered}
$$

From which, we can get:

$$
c=4.5056
$$

The following is the pricing formula of European put options with transaction costs:

$$
\begin{gathered}
p=X e^{-r(T-t)} N\left(-d_{2}\right)-S_{t} N\left(-d_{1}\right) \\
d_{1}=\frac{\ln \left(\frac{S_{t}}{X}\right)+\left(r+\frac{b_{1}{ }^{2}}{2}\right)(T-t)}{b_{1} \sqrt{T-t}} \\
d_{2}=d_{1}-b_{1} \sqrt{T-t} \\
b_{1}^{2}=b^{2}+2 \sqrt{\frac{2}{\pi \Delta t}} k b
\end{gathered}
$$

Which gives us:

$$
p=0.3522
$$

The overall results are as follows:

Table 1. The income formula for different positions of options and actual income.

\begin{tabular}{|c|c|c|}
\hline & $\begin{array}{c}\text { Without transaction } \\
\text { costs }\end{array}$ & With transaction costs \\
\hline Call option & $c=4.5112$ & $c=4.5056$ \\
\hline Put options & $p=0.3465$ & $p=0.3522$ \\
\hline
\end{tabular}

As the above results are calculated, we can ascertain that transaction costs have no significant influence on option prices when traders do not adjust the trading share frequently. Table 2 below shows that the transaction cost ratio has a negative relationship with the price of call options and a positive relationship with price of put options, whereas the frequency of adjustment exhibits inverse relationships with call and put options, compared to the transaction cost ratio. In essence, both of them 
change the volatility. Higher transaction cost ratios result in a lower volatility in call options and a higher volatility in put options. Yet, higher frequency of adjustment leads to a higher volatility in call options and a lower volatility in put options.

Table 2. How prices of options change with transaction cost ratios and frequency of adjustments

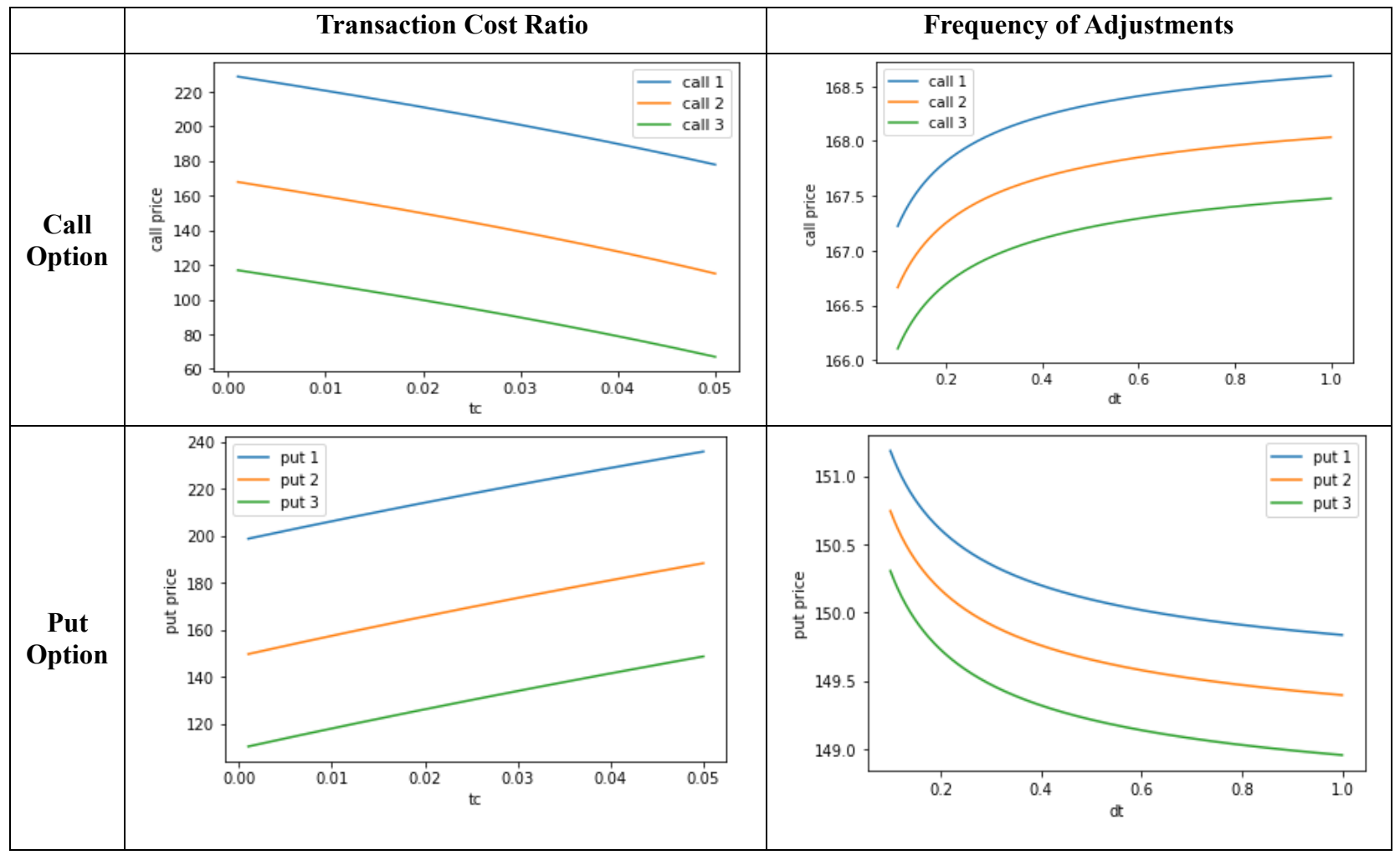

(Call 1 and Put 1 line in blue represent the in the money option, Call 2 and Put 2 in orange represent at the money option, and Call 3 and Put 3 in green represent out of the money option.)

\subsection{Volatility}

The transaction cost actually modifies the volatility of the subject matter price of derivatives. The specific relationship is as follows:

Call Options:

$$
b_{1}^{2}=b^{2}-2 \sqrt{\frac{2}{\pi \Delta t}} k b
$$

Put Options:

$$
b_{1}^{2}=b^{2}+2 \sqrt{\frac{2}{\pi \Delta t}} k b
$$

In the formula, $b_{1}$ can be understood as the volatility modified by the transaction cost.

\subsection{Empirical Analysis by Using AAPL options}

We use the AAPL dataset from Kaggel website which contains the trading records of 1/5/2016 and assume interest rate and volatility as originally implied.

By comparing Mean square error(MSE) among prices predicted by original model with MSE among prices predicted by extended model with transaction costs, we can get:
Table 3. Mean square error among prices of options predicted by different models.

\begin{tabular}{|c|c|c|}
\hline & $\begin{array}{c}\text { MSE for } \\
\text { call options }\end{array}$ & $\begin{array}{c}\text { MSE for } \\
\text { put options }\end{array}$ \\
\hline $\begin{array}{c}\text { With } \\
\text { transaction cost }\end{array}$ & 22.14499 & 24.21713 \\
\hline $\begin{array}{c}\text { Without } \\
\text { transaction cost }\end{array}$ & 22.16834 & 24.24409 \\
\hline
\end{tabular}

MSE among prices predicted by extended model with transaction costs is lower which means that the extended model gives a better prediction for option prices.

What's more, by listing all the prices simulated by extended model with transaction costs, we can get: 
Table 4. Simulation for call option prices.

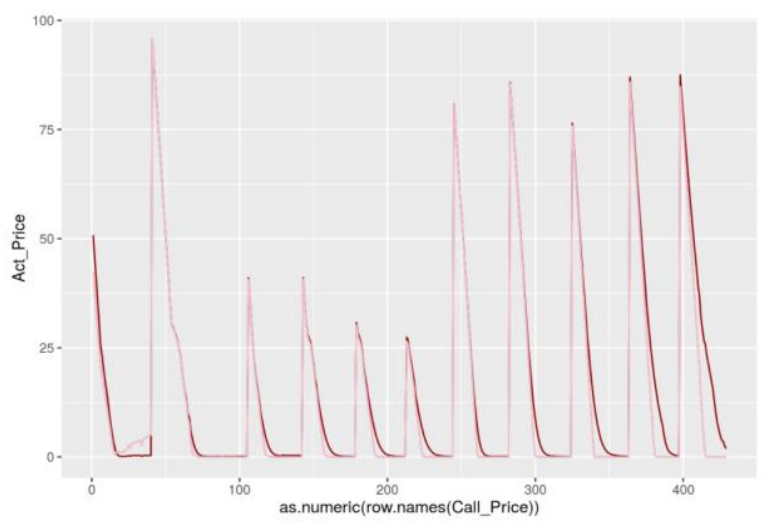

Table 5. Simulation for put option prices.

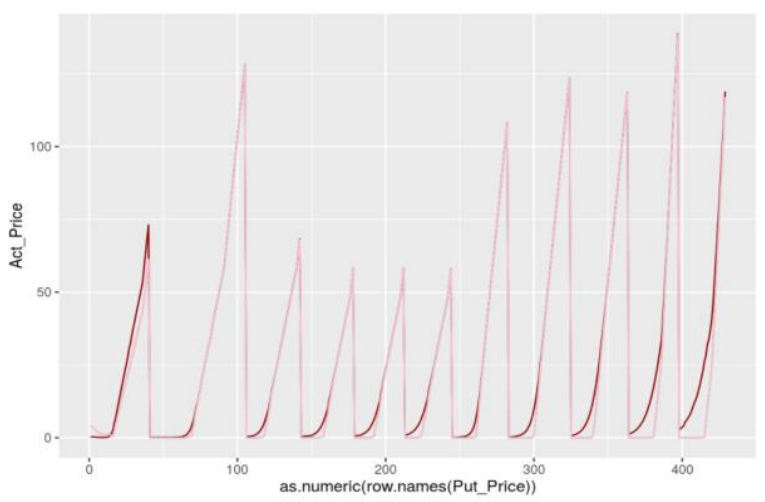

The $\mathrm{X}$-axis represents the serial number for options listed in dataset and the Y-axis represents the option prices. The pink line represents the real-world prices and the dark red one represents the prices predicted by extended model with transaction costs. As shown, we can find that our simulation has a great fitness.

\subsection{Greek Letter}

Gamma is another factor which would influence transaction costs in real world trading, because dealers or investors usually hedge their derivatives by purchasing a certain amount of underlying assets, which can result in dramatic fluctuations in prices of both options and underlying assets.

Recently, the Softbank Group Corporation made significant purchases of call options on some of the world's most popular technology stocks, including Tesla, Netflix, and Amazon. As a result, the prices of both the call options and underlying stocks experienced a dramatic increase.

$$
\text { Delta }=\text { Gamma } * \Delta S
$$

The dramatic increase can be explained by Greek letters Delta and Gamma. After a large amount of call options are purchased by Softbank, the dealers needed to hedge the risk by buying Delta stocks in the market to make the Delta neutral. Yet as the trading volume of Softbank's transaction is relatively high, the vast buy orders in the stock market would drive the stock price up.
As we know, Delta is not constant, and changes by Gamma times the amount of price change. The call options brought by Softbank have a positive Gamma (for most call options, Gamma is positive) and the Delta would increase with the increase of stocks' prices. In other words, the dealers needed to buy more stocks to make the Delta neutral, while more buy orders would continuously raise the stock price and Delta. In short, the Gamma issue leads to the mutual promotion between Delta and trading volume, which is the nature of dramatic ascent of both stock and call option price.

Gamma is thus an important issue that influences the transaction costs, particularly when the trading volume is high.

\section{CONCLUSION}

The Black-Scholes option pricing model, and variants which are more in line with the market realities, have been studied and improved by many scholars. In fact, although the final results of all the studies are very different, up until now, a perfect pricing method is yet to emerge. Especially when transaction costs are taken into account, there is a lot of room for the relevant models to be improved, since the cost is more than the transaction costs of the stock, and its structure may be discrete. In order to adapt to the changing rules of market capital price changes, we need a model that should be more in line with the reality of the market. In the original BlackScholes option pricing model, transaction expenses (costs) were not added to the model as a variable, but such cost are directly neglected. However, in the actual transaction, facing different customers of the exchange, there may be a completely different transaction fee environment for different derivative products of the same subject, or different transaction quantities of the same derivative product. In particular, when some investors frequently trade in order to avoid risks as much as possible, while making a small profit, the transaction cost will gradually become significant and ensure the initial model gradually deviates from the actual situation.

For the simplicity of derivation and calculation, in this paper, we consider option pricing model with transaction costs only through the variable of the transaction volume and concluded the impact of the frequency of transaction volume adjustments in application. However, we cannot encompass the influence of price fluctuations caused by Liquidity or Gamma into our extension model.

\section{Appendix I}

Starting from the Wiener process:

$\frac{\partial s_{t}}{s_{t}}=r \Delta t+b d W$

Where, $\partial S_{t}=S_{t+\Delta t}-S_{t}$ and $d W=W_{t+\Delta t}-W_{t}$. 
The transaction costs of stock can be represented by $k|n| S, k$ is the transaction cost ratio based on the price of stock and $\mathrm{n}$ is the trading volume of stock. When the $\mathrm{n}$ is greater than 0 , it means that we buy the stock and when the $\mathrm{n}$ is less than 0 , it means that we sell the stock.

We build the portfolio: $\Pi_{t}=n_{t}-\Delta_{t} S_{t}$,

And within $\left[t, t+\Delta_{t}\right]$,

$$
\Delta \Pi_{t}=n_{t}-\Delta t \partial S_{t}-k\left|n_{t}\right| S_{t+\Delta t}
$$

By using Itō-Doeblin formula,

$\Delta \Pi_{t}=\left(\frac{\partial n}{\partial t}+\frac{1}{2} b^{2} S^{2} \frac{\partial^{2} n}{\partial S^{2}}\right) \Delta t+\left(\frac{\partial n}{\partial S}-\Delta t\right) \partial S_{t}-k\left|n_{t}\right| S_{t+\Delta t}$

Substituting $\Delta t=\frac{\partial n}{\partial S}$, we can get:

$$
\Delta \Pi_{t}=\left(\frac{\partial n}{\partial t}+\frac{1}{2} b^{2} S^{2} \frac{\partial^{2} n}{\partial S^{2}}\right) \Delta t-k\left|n_{t}\right| S_{t+\Delta t}
$$

Then, $\quad \mathrm{S}_{t+\Delta t}=S_{t}+b S_{t} d W+O(\Delta t)$

Where $O(\Delta t)$ is the higher-order formula about $\Delta t$.

$$
\begin{array}{r}
E\left(k\left|n_{t}\right| S_{t+\Delta t}\right)= \\
+O(\Delta t) \\
+O S_{t}\left|\frac{\partial^{2} n}{\partial S^{2}}\right|_{t} E\left[\left|d W_{t}\right|\left(S_{t}+b S_{t} d W_{t}\right)\right] \\
=k b S_{t}^{2}\left|\frac{\partial^{2} n}{\partial S^{2}}\right|_{t} E\left[\left|d W_{t}\right|+b E\left(\left|d W_{t}\right| d W_{t}\right)\right]+O(\Delta t) \\
E\left|d W_{t}\right|=\int_{-\infty}^{+\infty}|x| \frac{1}{\sqrt{2 \pi \Delta t}} \exp \left(-\frac{x^{2}}{2 \Delta t}\right) d x \\
=\int_{0}^{+\infty} 2 x \frac{1}{\sqrt{2 \pi \Delta t}} \exp \left(-\frac{x^{2}}{2 \Delta t}\right) d x \\
=\int_{0}^{+\infty} \sqrt{\frac{2 \Delta t}{\pi}} \exp \left(-\frac{x^{2}}{2 \Delta t}\right) d\left(\frac{x^{2}}{2 \Delta t}\right)=\sqrt{\frac{2 \Delta t}{\pi}} \\
E\left(\left|d W_{t}\right| d W_{t}\right)=\int_{-\infty}^{+\infty} x|x| \frac{1}{\sqrt{2 \pi \Delta t}} \exp \left(-\frac{x^{2}}{2 \Delta t}\right) d x=0
\end{array}
$$

We can get,

$$
E\left(k\left|n_{t}\right| S_{t+\Delta t}\right)=\sqrt{\frac{2}{\pi}} k b S_{t}^{2}\left|\frac{\partial^{2} n}{\partial S^{2}}\right|_{t} \sqrt{\Delta t}+O(\Delta t)
$$

Therefore,

$$
\begin{aligned}
\Delta \Pi_{t}=\left(\frac{\partial n}{\partial t}+\frac{1}{2} b^{2}\right. & \left.S^{2} \frac{\partial^{2} n}{\partial S^{2}}\right) \Delta t-\sqrt{\frac{2}{\pi}} k b S_{t}^{2}\left|\frac{\partial^{2} n}{\partial S^{2}}\right|_{t} \sqrt{\Delta t} \\
& =r\left(n_{t}-\Delta t S_{t}\right) \Delta t
\end{aligned}
$$

Which means,

$$
n_{t}^{\prime}+\frac{1}{2} b^{2} S^{2} n_{t}^{\prime \prime}+r S \frac{\partial n}{\partial S}-r n-\sqrt{\frac{2}{\pi \Delta t}} k b S_{t}^{2}\left|\frac{\partial^{2} n}{\partial S^{2}}\right|=0
$$

Finally, we can get our solution:

$$
b 1= \begin{cases}b^{2}-2 \sqrt{\frac{2}{\pi \Delta t} k b,} & n>0 \\ b^{2}+2 \sqrt{\frac{2}{\pi \Delta t} k b,} & n<0\end{cases}
$$

So, for call option:

$$
\begin{gathered}
c=S_{t} N\left(d_{1}\right)-X e^{-r(T-t)} N\left(d_{2}\right) \\
d_{1}=\frac{\ln \left(\frac{S_{t}}{X}\right)+\left(r+\frac{b_{1}^{2}}{2}\right)(T-t)}{b_{1} \sqrt{T-t}} \\
d_{2}=\frac{\ln \left(\frac{S_{t}}{X}\right)+\left(r-\frac{b_{1}^{2}}{2}\right)(T-t)}{b_{1} \sqrt{T-t}}=d_{1}-b_{1} \sqrt{T-t} \\
b_{1}^{2}=b^{2}-2 \sqrt{\frac{2}{\pi \Delta t}} k b
\end{gathered}
$$

For put option:

$$
\begin{gathered}
p=X e^{-r(T-t)} N\left(-d_{2}\right)-S_{t} N\left(-d_{1}\right) \\
d_{1}=\frac{\ln \left(\frac{S_{t}}{X}\right)+\left(r+\frac{b_{1}{ }^{2}}{2}\right)(T-t)}{b_{1} \sqrt{T-t}} \\
d_{2}=d_{1}-b_{1} \sqrt{T-t} \\
b_{1}^{2}=b^{2}+2 \sqrt{\frac{2}{\pi \Delta t}} k b
\end{gathered}
$$

\section{REFERENCES}

[1] Black, F., \& Scholes, M. S. (1973). The pricing of options and corporate liabilities. Journal of Political Economy, 81(3), 637-654.

[2] Black, F. (1975). Fact and fantasy in the use of options, Financial Analysts Journal 31, no.4,36-41 and 61-72.

[3] Black, F. (1971)."Toward a Fully Automated Exchange." Financial Analysts Journal, Parts I and II.

[4] Bouchaud, J. P., \& Sornette, D. (1994). The blackscholes option pricing problem in mathematical finance: generalization and extensions for a large class of stochastic processes. ence \& Finance Working Paper Archive, 4(6), 464a.

[5] Donald P. Chiras., \& Steven Manaster. (1978). The information content of option prices and a test of market efficiency, Journal of Financial Economics, 6(2-3), 213-234.

[6] Emanuel, P. (1962). Stochastic process. Technometrics, 5(4).

[7] Geske, R. (1979). The valuation of compound options. Journal of Financial Economics, 7(1), 63-81. 
[8] Itō, K. (1944): Stochastic integral. Proc. Imp. Acad. Tokyo 20, 519-524.

[9] John, C., Cox, and, Stephen, \& A. (1976). The valuation of options for alternative stochastic processes. Journal of Financial Economics.

[10] John E., Gilster, Jr. and William Lee. (1984) The Effects of Transaction costs and Different Borrowing and Lending Rates on the Option Pricing Model: A Note, Journal of Finance, 39(4), 12151221.

[11] Merton, R. C. (1976). Option pricing when underlying stock returns are discontinuous. Journal of Financial Economics, 3(1), 125-144.

[12] Mittnik, S. \& Rachev, S.T. (1999). Option pricing for stable and infinitely divisible asset returns. Mathematical and Computer Modelling, 29(s 1012), 93-104.

[13] Wilmott, P., Hoggard, T. and Whalley, A. Elizabeth. (1994) Hedging Option Portfolios in the Presence of Transaction Costs. ADVANCES IN FUTURES AND OPTIONS RESEARCH, Volume 7, WBS Finance Group Research Paper No. 4. 